\title{
Probable Maximum Precipitation (PMP) Analysis for Bakun Dam Area
}

\author{
Yiau, S.S. and F.J. Putuhena
}

\begin{abstract}
Probable Maximum Precipitation is defined as the greatest depth of precipitation which is possible for a given time and duration over a given size storm area under known meteorological conditions. This concept has been used as design criterion of major flood control measures such as spillways of large dams worldwide. It is essential for the generation of Probable Maximum Flood. This paper represents the results of PMP analysis for Bakun Dam Area which has a catchment area of 14,750 km². Three sets of results were produced, i.e. by statistical method (with frequency factors from World Meteorological Organization manual and National Hydraulic Research Institute of Malaysia in Technical Research Publication No. 1 (TRP 1)) for duration of 1 hour, 8 hours, 24 hours and daily and by experimental method for production of daily PMP. The results were compared with each other and the one made by Sarawak Electricity Supply Corporation on Bakun Dam construction. The set of PMP values results from substitution of $\mathrm{K}_{\mathrm{m}}$ developed by NAHRIM was concluded to be the most reliable results as daily PMP $(276 \mathrm{~mm})$ was consistent with the one $(280 \mathrm{~mm})$ produced by SESCO. However, 6 days PMP value $(950 \mathrm{~mm})$ done by SESCO was recommended as the Bakun Dam Area cover huge catchment area which higher duration of PMP value should be applied.
\end{abstract}

Keywords: Probable Maximum Precipitation, Bakun Dam, PMP, Statistical Method, Frequency Factor.

\section{INTRODUCTION}

$\mathrm{F}^{\mathrm{s}}$ OR precipitation, there is a physical upper limit to the amount of precipitation which can fall over a specified area in a given time and known as the Probable Maximum Precipitation (PMP). It is precisely defined as "theoretically greatest depth of precipitation for a given duration that is physically possible over a given size storm area at a particular geographical location at a certain time of the year" [1]. The depth-area-duration relationship plays an important role in the design of hydraulic structures such as dams, weirs, and flood control structures.

Generally, dam failures occur as a result of overtopping due to inadequate spillway design. Over the world, there are about one-third of all dam failures induced by inadequate spillway design [2]. Inadequate spillway capacity is usually caused by underestimating the peak flow or volume of the design flood. Design criteria of spillway are normally based on the PMF transforming from the PMP of critical duration over a given catchment area. Thus the PMP value is useful and essential in forming the PMF hydrograph which has become the design standard for dams throughout the world without risk of overtopping.

Bakun Hydroelectric Dam is located in Sarawak, Malaysia on Balui River which is a tributary of Rajang River, the longest river in Malaysia and around sixty kilometer west of Belaga. In specific, the dam is located at $2^{\circ} 45^{\prime} 23^{\prime \prime}$ north in latitude and $114^{\circ} 3^{\prime} 47^{\prime \prime}$ east in latitude. Rajang River consists of two parts that are Lower Rajang and Upper Rajang. Bakun Dam area is situated within Upper Rajang. The created Bakun Reservoir has a capacity of about $43,800,000,000 \mathrm{~m}^{3}$ with catchment area of $14,750 \mathrm{~km}^{2}$, representing $11 \%$ of the state of Sarawak [3]. The catchment area is covered mainly by primary jungles on mountainous terrain and steep slopes and the rest by second forest with lower slopes.

Theoretically, estimates of PMP should have zero exceedence probability. However, PMP estimates have been exceeded by the observed rainfall depth in some cases reveals that the PMP approach "by no means implies zero risk in reality" [4]. Thus, methods used for driving PMP should include making judgments based on observed storms and related meteorological process. Besides, to minimize the error come with PMP approach, historic heavy storms over the area of study should be

Yiau, S.S., undergraduate student, Universiti Malaysia Sarawak, Kota Samarahan 94300 Malaysia (e-mail: yss0708@yahoo.com).

F.J. Putuhena, lecturer, Department of Civil Engineering, Universiti Malaysia Sarawak, Kota Samarahan 94300 Malaysia (e-mail: fjputuhena@feng.unimas.my). 
considered in evaluate the PMP values and also correlate the spots of storm occurring within the study area. This can lead to an advanced accuracy of evaluated PMP values and a more realistic representation of PMP.

\section{METHODS OF PMP ESTIMATION}

Varies methods are available in estimating Probable Maximum Precipitation and is dependent with each others as the variables are considered inter-related. According to Wiesner (1970), the techniques that have been used are as follows [5]:

\section{a. The storm model approach}

It is a logical method which uses the assumed maximum values of variables in the precipitation equation to extrapolate precipitation to its probable extreme. The rainfall intensity of storm model is mainly depends upon the geometrical basin factor $(\mathrm{K})$, inflow velocity $(v)$, moisture factor $(W)$, and convergence factor $(p)$ as shown in the equation below:

$$
\text { Rainfall intensity, } i=\mathrm{K} \cdot v_{12} W_{12}\left\{1-\frac{\Delta p 12}{\Delta p 34} \cdot \frac{W 34}{W 12}\right\}
$$

There are mainly two types of storm models that upglide model and convergent model. The upglide model is typically for orographical rainfall while convergent model is for thunderstorm and tropical cyclone. This approach is selected to estimate the PMP when there is insufficient or unrepresentative storm data, rugged topography or a degree of rationalization and consistency is needed. However, this model is not suit to be use for small areas due to difficulties of precision measuring of required factors (mentioned above) and express them in an appropriate way [2].

\section{b. The maximization and transposition of actual storm}

It is the most convenient and acceptable form of obtaining the PMP. Transposition of storm is basically transforming the recorded storm characteristics from one or more areas to the given area (gauged location to ungauged location) while storm maximization includes adjustment on observed precipitation amount to its maximum moisture convergence [6]. The rainfall depths which are expressed in isohyetal maps or depth-duration-area (D.D.A.) values are used together with representative dew point and maximum dew point to give the PMP values for the specified basin. This approach covers the deficiency of storm models in topographical intensification, spillover and variable storm efficiencies.

c. The used of generalized data or maximized depth, duration and area data from storms, these are derived from thunderstorms or general storms

In usual, generalized approaches involve maximization and transposition of classes of storms over a wide region. It is used to obtain more reliable and consistent estimates of PMP and if there is lack of storm history or insufficient record of highly efficient storms. PMP estimations can be obtained based on a list of greatest recorded rainfall depths for various durations at rain gauges or point rainfalls as well as from the analyzed DDA data. This is done by gather together all the rainfalls data from a very large area and standardized the rainfall depths [7].

\section{d. The use of empirical formulae determined from maximum depth, duration and area data or from theory}

Commonly, empirical formulae represent local or world maximum values of precipitation in point values instead of areal accumulations [8].Use of empirical formulae is likely to be the easiest way to estimate PMP. The currently available empirical formulae used to estimate PMP is originally derived from the world's highest gauge rainfalls and given the formulae as below:

$$
P=16.6 D^{0.475}
$$

where 16.6 is a constant, $D$ is the duration in hours and $P$ is the accumulation of point rainfalls in inches. Results of heavy rainfalls studies in other areas had indicated the notable changes in the constant of proportionality but constant for the exponent of $\mathrm{D}$ that approximates to 0.5 [5]. Thus, $P$ varies as $\approx \sqrt{ } D$ for the world's highest gauge rainfalls is only suit to be applied for specific duration while intense storms with long duration need exceptional conditions such as favorable topography. However, maximization and transposition of storms is always preferred if it is allowable and the original data is available with the appropriate adjustments instead of using the empirical formula.

e. The use of empirical relationships between the variables in particular valleys or basins (only if detailed data are available) 
For a specific valley, the optimum wind velocity and surface dew point are the key factors in estimating maximum rainfalls due to their high consistency and amenable to statistical treatment and extrapolation. And normally, convergence factor is assumed to reach its maximum values in a valley's intense storm history and is disregarded. Therefore, a rainfall formula is directly relating the rainfall intensity over the valley to the wind velocity and the surface dew point with the constant derived from the intense storm history. This technique is applicable in mountainous areas with complex topography when there is insufficient of data and manpower to carry out storm model research.

\section{f. Statistical analyses of extreme rainfalls}

It is a quick approach to estimate the PMP typically for rain gauge recorded data and when site-specific data are unavailable. This method is preferred majorly because of its fast estimation and ease to use if compare to the meteorological approaches. However, it does not include the local influences on the storm or its features which may be considerable [2]. This method will produce only point values of PMP and need to be converted to various sizes of area by an Area Reduction Factor (ARF) gain from area - reduction curves.

One of the methods which standardized by WMO (1986) is based on Hershfield (1961, 1965) procedures. The maximum observed rainfall, $\mathrm{X}_{\mathrm{m}}$, can be defined from:

$$
\mathrm{X}_{\mathrm{m}}=\overline{\mathrm{X}}_{\mathrm{n}}+\mathrm{K}_{\mathrm{m}} \mathrm{S}_{\mathrm{n}}
$$

where $\bar{X}_{n}$ and $S_{n}$ are respectively the mean and standard deviation of the $n$ annual maximum precipitation series and $K_{m}$ is maximum frequency factor which varies with statistical distributions and other meteorological data. Mostly, this method is used for basins with area less than $1000 \mathrm{~km}^{2}$ as problem is encountered when converting rain gauge data to larger area due to the high precipitation rate. However, it has been used for larger area [1].

There is an experimental formula presented by Irish and Schenk (1981) through simplification of the Hershfield method:

$$
\mathrm{PMP}=6 \times \mathrm{P}_{\text {max,av }}
$$

where $\mathrm{P}_{\text {max,av }}$ is average annual maximum daily rainfall $(\mathrm{mm})$. This formula had been successfully applied for Java and Sumatra in Indonesia where the average annual maximum 1-day point rainfalls are in the order of 100 to $180 \mathrm{~mm}$ [8].

Estimations of PMP by meteorological methods are mainly deal with maximum moisture available and the highest storm efficiency. Storm efficiency is the ratio of maximum observed rainfall to the amount of precipitable water in the storm column [2]. It is affected by various factors include atmospheric convergence, frontal, convective, or topographically induced lifting, vertical velocities and the rate of water vapor condensation [9].

In Sarawak, the method that had been applied by SESCO especially during determining the PMP for Bakun Dam construction was through depth-area-duration analysis for five most severe major storms recorded in Sarawak for duration of 1 to 6 days with combination of appropriate transposition and moisture maximization adjustments.

The main purpose of this project is to make PMP analysis on Bakun Dam Area. In this study, the Statistical Method and Experimental Method were used to estimate the PMP on Bakun Dam Area as they involved actual storm data and there were adequate data to conduct it. While other meteorological data like dew points and moisture content which are essential in other methods were not available.

\section{Methodology}

\section{i. Rainfall Data Assessment}

By reviewing the rainfall data collection in Upper Rajang River basin, a decision regarding the selection of appropriate and suitable rainfall stations that can be used for this study was done. The rainfall station should be automatic function like recorder and HS-logger, not manually function due to the requirement of continuous rainfall data. The available longest records data should be at least up to 20 years.

\section{ii. Storms Assessment}


Annual maximum hourly (1-h, 8-h and 24-h) and daily rainfall data for 21 years (from year 1989 until year 2009) was used for this study. These data were obtained from Department of Irrigation and Drainage (DID) Sarawak. Those storms information and rainfall data are required to study the storm characteristic on depth, duration and areal coverage for Bakun dam area which is important factors in estimating the PMP.

\section{iii. Method Used for Estimating PMP}

The statistical approach applied in this study was in accordance to World Meteorological Organisation manual (1986). The following are the procedures of statistical method to calculate the PMP [1]:

1. Conventional method was used to compute the mean $\left(\overline{\mathrm{X}}_{\mathrm{n}}\right)$ and standard deviations $\left(\mathrm{S}_{\mathrm{n}}\right)$ of the annual series selected.

2. The mean $\left(\overline{\mathrm{X}}_{\mathrm{n}-\mathrm{m}}\right)$ and standard deviations $\left(\mathrm{S}_{\mathrm{n}-\mathrm{m}}\right)$ of the annual series were computed without including the maximum rainfall amount in each series.

3. The ratio of $\bar{X}_{n-m}$ over $\bar{X}_{n}$ and $S_{n-m}$ over $S_{n}$ for each series were obtained.

4. $\bar{X}_{n}$ and $S_{n}$ for maximum observed rainfall were adjusted by means of figure 4.2 and 4.3 , respectively, and for record length by means of figure 4.4 .

5. From figure 4.1 , values of $\mathrm{K}_{\mathrm{m}}$ corresponding to adjusted values of $\overline{\mathrm{X}}_{\mathrm{n}}$ for the various durations were obtained.

6. Point values of PMP or $\mathrm{X}_{\mathrm{m}}$ were computed as indicated by (3).

7. Since the basic rainfall data are for fixed time intervals, the obtained PMP were adjusted upward by applying the factor 1.13 for fixed observational periods otherwise by means of figure 4.5.

*Figure 4.1 to Figure 4.5 referred to WMO manual [1].

Besides the way mentioned about, the $\mathrm{K}_{\mathrm{m}}$ were also obtained based on the equations of $\mathrm{K}_{\mathrm{m}}$ envelope curves developed by the NAHRIM for East Malaysia. The equations are as following:

$$
\begin{aligned}
& \text { For 1 hour: } \mathrm{y}=0.0005 \mathrm{x}^{2}-0.1168 \mathrm{x}+11.386 \\
& \text { For 1-day: } \mathrm{y}=6 \mathrm{E}-05 \mathrm{x}^{2}-0.0467 \mathrm{x}+12.885
\end{aligned}
$$

Where y represent $\mathrm{K}_{\mathrm{m}}$ and $\mathrm{x}$ represent mean maximum rainfall $(\mathrm{mm}), \overline{\mathrm{X}}_{\mathrm{n}}[10]$.

\section{iv. Comparable Method Used}

The dependency and reliance on actual data of the statistical method and also its ways of calculation indicated that this method should be applied and used together with other method. The comparable method used was the simplified equation on the Hershfield method which defined by Irish and Schenk (1981). This equation (refer to (4)) had been experimentally applied on Java and Sumatra in Indonesia. Since Malaysia (especially Sarawak) have similar climate with Indonesia, this experimental equation was assumed to be applicable to this study. Besides used to do the PMP estimates, this method also used to check the consistency and reliability of the statistical method since there were adequate data for applying this method.

\section{v. Justification of Results}

The evaluated PMP results from both the statistical approach and experimental equation were justified with the storm conditions that had been recorded. Besides, the results were compared with the PMP from recorded storms by SESCO and also between both the methods that had been used.

\section{RESULTS, ANALYSIS AND DISCUSSION}

Based on the rainfall data obtained from DID, four qualified rainfall stations were selected that are Long Jek, Long Laku, Long Lidam (formerly Punan Busang) and Long Unai. These four rainfall stations cover up the Bakun catchment area as Long Jek located at the upper part of the Bakun catchment boundary, Long Laku and Long Lidam are both located at the middle part of Bakun Basin while Long Unai are located at the bottom part. In this project, the hourly and daily annual maximum precipitation data from year 1989 to 2009 was used for PMP estimation. Hourly precipitation data obtained from DID was analyzed to find out the annual maximum hourly rainfall value. Same way was adopted for PMP analysis of 8 hours and 24 hours which were based on the cumulative hourly data.

The Probable Maximum Precipitation estimates of 1 hour, 8 hours, 24 hours and daily for every rainfall station by Statistical Method were summarized in Table 1. 
Table 1: Probable Maximum Precipitation for Bakun Dam Area by Statistical Method

\begin{tabular}{c|c|c|c|c|c|c|c|c}
\hline \multirow{2}{*}{$\begin{array}{c}\text { Rainfall } \\
\text { Station }\end{array}$} & \multicolumn{2}{|c|}{} & \multicolumn{2}{c}{ Duration (hour) } \\
\cline { 2 - 9 } & Fg. & Eqs. & Fg. & Eqs. & Fg. & Eqs. & Fg. & Eqs. \\
\hline Long Jek & $251 \mathrm{~mm}$ & $189 \mathrm{~mm}$ & $489 \mathrm{~mm}$ & - & $652 \mathrm{~mm}$ & $423 \mathrm{~mm}$ & $674 \mathrm{~mm}$ & $438 \mathrm{~mm}$ \\
\hline Long Laku & $162 \mathrm{~mm}$ & $130 \mathrm{~mm}$ & $323 \mathrm{~mm}$ & - & $445 \mathrm{~mm}$ & $303 \mathrm{~mm}$ & $491 \mathrm{~mm}$ & $334 \mathrm{~mm}$ \\
\hline Long Lidam & $198 \mathrm{~mm}$ & $157 \mathrm{~mm}$ & $292 \mathrm{~mm}$ & - & $410 \mathrm{~mm}$ & $282 \mathrm{~mm}$ & $389 \mathrm{~mm}$ & $276 \mathrm{~mm}$ \\
\hline Long Unai & $241 \mathrm{~mm}$ & $190 \mathrm{~mm}$ & $431 \mathrm{~mm}$ & - & $531 \mathrm{~mm}$ & $354 \mathrm{~mm}$ & $578 \mathrm{~mm}$ & $385 \mathrm{~mm}$ \\
\hline
\end{tabular}

*Fg. represent the PMP estimate is based on $\mathrm{K}_{\mathrm{m}}$ obtained from figure 4.1 [1]

*Eqs. represent the PMP estimate is based on $\mathrm{K}_{\mathrm{m}}$ obtained from equations of $\mathrm{K}_{\mathrm{m}}$ envelop curves.

The average annual maximum daily rainfall calculated previously (mean precipitation, $\mathrm{X}_{\mathrm{n}}$ ) was substituted into (4) to obtain the PMP value. The results of PMP for the four selected rainfall stations through Experimental Method were indicated in the table 2.

Table 2: Probable Maximum Precipitation for Bakun Dam Area by Experimental Equation

\begin{tabular}{c|c|c|c|c}
\hline \multirow{2}{*}{ Rainfall (mm) } & \multicolumn{4}{|c}{ Rainfall Stations } \\
\cline { 2 - 5 } & Long Jek & Long Laku & Long Lidam & Long Unai \\
\hline $\mathrm{P}_{\text {max,av }}$ & 88.8 & 98.6 & 99.2 & 104.4 \\
\hline PMP & 533 & 592 & 595 & 626 \\
\hline$* \mathrm{P}_{\text {max av }}=$ average annual maximum daily rainfall (mm)
\end{tabular}

\section{a) Comparison of PMP Estimates for Statistical Method with Frequency Factor $\left(K_{m}\right)$ from WMO and NAHRIM}

From Table 1, the PMP estimates for all duration with Fg. were basically higher than the one with Eqs.. It is because the $\mathrm{K}_{\mathrm{m}}$ developed by NAHRIM is much lower than the one indicated by WMO. The PMP value calculated by WMO procedures did not adjusted by area-reduction factor which may give lower PMP value. For daily, the PMP range from $400 \mathrm{~mm}$ to 600 $\mathrm{mm}$ and from $280 \mathrm{~mm}$ to $380 \mathrm{~mm}$ respectively with substitution of $\mathrm{K}_{\mathrm{m}}$ from figure and equations in estimations except the Long Jek which were $674 \mathrm{~mm}$ and $438 \mathrm{~mm}$. This may due to its geographical location which receives higher amount of rainfall compared to the other three rainfall stations.

The difference of PMP values of 1 day duration for 4 rainfall stations resulted from WMO procedure was about 300 mm which was twice as much of the one with $\mathrm{K}_{\mathrm{m}}$ from NAHRIM that is only with $160 \mathrm{~mm}$ divergence. This implied that the PMP estimates were more consistent by using frequency factor $\left(\mathrm{K}_{\mathrm{m}}\right)$ from NAHRIM which was particularly developed for East Malaysia and more suitable to be used if area-reduction factor is not available.

\section{b) Comparison of PMP Estimates between Statistical Method and Experimental Method}

As for Table 2 which used the experimental equation, the PMP estimates were range from $500 \mathrm{~mm}$ to $600 \mathrm{~mm}$ which having similar results with the statistical results of WMO procedures. This implied that experimental method is consistent with the WMO procedures. However, the Long Jek gave the highest PMP value among the 4 rainfall stations with statistical method while lowest value was obtained with experimental equation. It was deduced that the experimental equation was applied larger safety factor and may simply for experiment purpose only.

\section{c) Comparison of PMP Estimates at Long Lidam with PMP Estimates by SESCO at Feasibility Report, 1983}

In estimating the PMP value for Bakum Dam Area, SESCO had done the preliminary PMP analysis on Upper Rajang River Basin which comprise of Bakun catchment area and Pelagus catchment area. They considered the rainfall event for duration of 1 day until 6 days. The derived PMP values for various durations by SESCO were showed in Table 3 below: 
Table 3: Probable Maximum Precipitation (mm) [11]

\begin{tabular}{|c|c|c|c|c|c|c|}
\hline \multirow{2}{*}{$\begin{array}{c}\text { Catchment } \\
\text { Area }\end{array}$} & \multicolumn{6}{|c|}{ Duration in Days } \\
\hline & 1 & 2 & 3 & 4 & 5 & 6 \\
\hline $\mathrm{A}$ & 390 & 530 & 730 & 880 & 1030 & 1080 \\
\hline B & 280 & 430 & 620 & 780 & 900 & 950 \\
\hline $\mathrm{C}$ & 210 & 360 & 540 & 700 & 820 & 870 \\
\hline \multicolumn{7}{|c|}{$\begin{array}{l}\text { Area } A-\quad 6,270 \mathrm{~km}^{2} \text { (about Pelagus, below Bakun) } \\
\text { Area B }-\mathbf{1 4 , 7 5 0} \mathbf{~ k m}^{2} \text { (above Bakun) } \\
\text { Area } C-21,020 \mathrm{~km}^{2} \text { (total above Pelagus) }\end{array}$} \\
\hline
\end{tabular}

From the table above, the estimated 1 day PMP value by SESCO was $280 \mathrm{~mm}$. When comparing this value with the one at Long Lidam, it was deduced that the PMP value $\left(276 \mathrm{~mm}\right.$, with $\mathrm{K}_{\mathrm{m}}$ from NAHRIM) at Long Lidam was consistent with PMP estimated by SESCO. Thus, the daily PMP values resulted from statistical method with frequency factor from NAHRIM were more reliable. Nevertheless, SESCO used 6 days PMP value (950mm) for PMF evaluation as the Bakun Dam Area cover huge catchment area which higher duration of PMP value should be applied.

\section{d) Assumptions for Probable Maximum Precipitation (PMP) Estimations}

The Long Jek, Long Laku, Long Lidam and Long Unai rainfall stations were considered to be part of Bakun's catchment as all of them are located within the Upper Rajang Basin. Besides, the 21 years rainfall data taken were recorded by chart recorder and HS-logger equipment. The chart recorder here was considered as automatic function equipment which produces continuously rainfall data as HS-logger equipment was only installed in Upper Rajang Basin after year 1998.

The statistical method used for PMP estimations in this study consists of two different frequency factors $\left(\mathrm{K}_{\mathrm{m}}\right)$. One was based on $\mathrm{K}_{\mathrm{m}}$ derived by WMO and another one was developed by NAHRIM. Both of these two frequency factors were assumed to be applicable for this case as the $\mathrm{K}_{\mathrm{m}}$ from WMO (empirical nomograph, refer to figure 4.1 [1]) was derived from worldwide data analysis while the $\mathrm{K}_{\mathrm{m}}$ from NAHRIM (refer to Equations (5) \& (6)) was developed particularly for East Malaysia.

When using the experimental equation in evaluating the PMP value, the climatic condition in Indonesia was assumed to be similar with Bakun Dam Area. This was justified as Indonesia especially Java and Sumatra which is closer to the tropical region has similar tropical weather condition as Sarawak state.

\section{e) Issues Arise in PMP Estimations}

The PMP estimated through WMO procedures in this case were not adjusted by area-reduction factor as the area-reduction curves developed by WMO (refer to figure 4.1 [1]) only applicable up to $1000 \mathrm{~km}^{2}$ where the Bakun Dam Area consist of $14,750 \mathrm{~km}^{2}$ catchment area. However, the WMO procedures was still been used to evaluate the PMP for Bakun Dam Area and the calculated point value of PMP were deduced to be higher than actual PMP for overall basin. Furthermore, the PMP estimates for all the four rainfall stations were not consistent with each other which were most probably due to this issue.

\section{CONCLUSIONS AND RECOMMENDATIONS}

The following conclusions can be drawn from this research.

- Among the four rainfall stations selected for PMP analysis for Bakun Dam Area, Long Jek gave the highest PMP values either with $\mathrm{K}_{\mathrm{m}}$ derived from $\mathrm{WMO}$ or $\mathrm{K}_{\mathrm{m}}$ developed by NAHRIM for all specified durations due to its geographical location that receives higher rainfall and storm activities.

- The experimental method produced PMP estimates at range $500 \mathrm{~mm}$ to $600 \mathrm{~mm}$ for daily duration which was consistent with the estimations of PMP by WMO procedures.

- The PMP evaluated at Long Lidam by Statistical Method with $\mathrm{K}_{\mathrm{m}}$ from NAHRIM was consistent with the PMP estimation for Bakun Dam by SESCO.

- The PMP evaluated through WMO procedures were point values with higher figure as the results were not adjusted by area-reduction factor (ARF) to areal-averaged amount whereas the catchment area of Bakun is $14,750 \mathrm{Km}^{2}$. 
- The set of PMP values (refer to Table 1) results from substitution of frequency factors $\left(\mathrm{K}_{\mathrm{m}}\right)$ developed by NAHRIM was concluded to be the most reliable results as the $\mathrm{K}_{\mathrm{m}}$ was typically for East Malaysia and the results were consistent as well with the one done by SESCO which considered the overall Bakun catchment area.

In estimating the PMP for Bakun Dam Area through Statistical Method, further studies and researches need to be performed in order to develop its own adjustment factors as in figure 4.1 to figure 4.5 in WMO manual [1]. It is always recommended to adopt the original data rather than using the one produced by other countries which may decrease the reliability of the results. Besides that, the area-reduction curves also need to be developed directly from the storm rainfall data for which PMP estimates are to be made. These studies need to be done to minimize any appreciable errors that might influence the accuracy of PMP estimations for Bakun Dam Area.

Furthermore, longer length of continuously recorded storm rainfall data should be used to obtain more accurate PMP at Bakun Dam Area as longer record will generate more reliable PMP estimates if compare to shorter record in the views of data quality and accuracy. If possible, take full length of continuously recorded rainfall data but not just limits to minimum 20 years as advised.

Other than that, PMP estimations for Bakun Dam Area should be carried out for longer durations which may up to 6-days as the catchment area is huge. Although storm at Sarawak state are normally of short durations (1 hour, 8 hours and 24 hours), longer durations of PMP estimates are needed for larger catchment area. This is justified as SESCO used 6-days PMP value to evaluate the Probable Maximum Flood (PMF) in designing spillway of Bakun Dam during the feasibility study.

\section{ACKNOWLEDGMENT}

Special thanks to Technical Assistant, Mr. Chai of Water Resources and Hydrology Division and other staffs of DID involved directly or indirectly in assisting and providing the rainfall data required for this project. Gratitude and acknowledgement are forwarded to the Senior Manager, Dr. Denis Lee Hau Aik and Assistant, Miss Lim Yung Hui of SESCO for their supports and cooperation in providing the relevant PMP data. The authors are thankful to the Faculty of Engineering, UNIMAS for supporting this paper.

\section{REFERENCES}

[1] Secretariat of the World Meteorological Organization. (1986). Manual for Estimation of Probable Maximum Precipitation: Second Edition, World Meteorological Organization Operational Hydrology Report No. 1. Geneva, Switzerland: World Meteorological Organization.

[2] Collier, C. G., \& Hardaker, P. J. (1996). Estimating probable maximum precipitation using a storm model approach. Journal of Hydrology, 183(3-4), 277-306. doi: 10.1016/0022-1894(95)02953-2

[3] Malaysia-China-Hydro. (2011). Bakun National Hydroelectric Project: Malaysia's future in clean energy. Retrieved August 4, 2010, from http://www.bakundam.com/

[4] Koutsoyiannis, D. (1998). A probabilistic view of Hershfield's method for estimating probable maximum precipitation. Retrieved from http://www.itia.ntua.gr/getfile/23/2/documents/1999WR900002PP.pdf

[5] Wiesner, C. J. (1970). Hyorometeorology. London: Chapman and Hall Ltd.

[6] Douglas, E. M., \& Barros, A. P. (2003). Probable Maximum Precipitation Estimation Using Multifractals: Application in the Eastern United States. Journal of Hydrometeorology, 4, 1012-1024. Retrieved from http://alpha.es.umb.edu/faculty/emd/files/Douglas \%26 Barros 2003.pdf

[7] Rakhecha, P. R., \& Kennedy, M. R. (1985). A Generalised Technique for the Estimation of Probable Maximum Precipitation in India. Journal of Hydrology, 78 (3-4), 345-359. doi: 10.1016/0022-1694(85)90112-X.

[8] Weert, R. V. D. (1994). Rainfall: Rainfall intensity-duration. Hydrological Conditions In Indonesia (p. 19). Jakarta: Delft Hydraulics.

[9] Svensson, C., \& Rakhecha, P. R. (1998). Estimation of Probable Maximum Precipitation for Dams in the Hongru River Catchment, China. Theortical and Applied Climatology. 59, 79-91. Retrieved from http://www.springerlink.com/content/nm3cjq08ahxucx5c/fulltext.pdf

[10] National Hydraulic Research Institute of Malaysia. (2008). Chapter 6 - Estimation of PMP Based on Statistical Method. In Hj. Ahmand Jamalluddin bin Shaaban et al. (Eds.), National Hydraulic Research Institute of Malaysia (NAHRIM) Technical Research Publication No.1 (TRP 1) - Derivation of Probable Maximum Precipitation for Design Floods in Malaysia. (pp. 6-1 - 6-15). Shah Alam: Ministry of Natural Resources and Environment, Malaysia.

[11] Sarawak Electricity Supply Cooperation, \& the National Electricity Board of Malaya. (1983). Bakum Hydro-electric Project, Feasibility Report, Volume III, Appendix E. Sarawak: German Agency for Technical Cooperation Ltd., SAMA Consortium. 